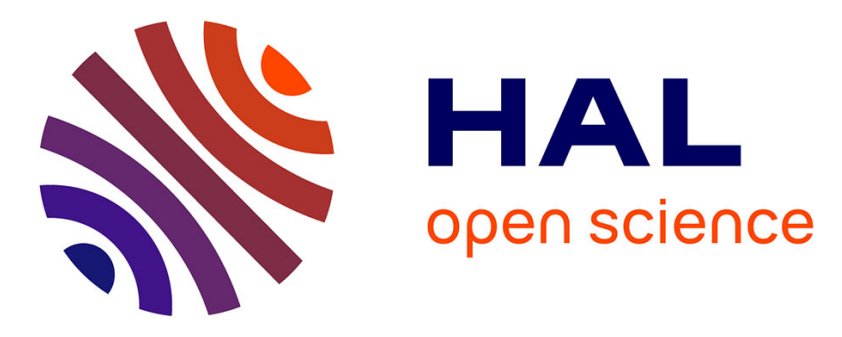

\title{
Gauges design for a digital instrument cluster: Efficiency, visual capture, and satisfaction assessment for truck driving
}

Mathilde Francois, Alexandra Fort, Philippe Crave, François Osiurak, Jordan Navarro

\section{To cite this version:}

Mathilde Francois, Alexandra Fort, Philippe Crave, François Osiurak, Jordan Navarro. Gauges design for a digital instrument cluster: Efficiency, visual capture, and satisfaction assessment for truck driving. International Journal of Industrial Ergonomics, 2019, 72, pp.290-297. 10.1016/j.ergon.2019.06.004 . hal-03186314

\section{HAL Id: hal-03186314 https://hal.science/hal-03186314}

Submitted on 31 Mar 2021

HAL is a multi-disciplinary open access archive for the deposit and dissemination of scientific research documents, whether they are published or not. The documents may come from teaching and research institutions in France or abroad, or from public or private research centers.
L'archive ouverte pluridisciplinaire HAL, est destinée au dépôt et à la diffusion de documents scientifiques de niveau recherche, publiés ou non, émanant des établissements d'enseignement et de recherche français ou étrangers, des laboratoires publics ou privés. 


\section{Manuscript Details}

\section{Manuscript number}

Title

Article type
ERGON_2019_21

Gauges design for a digital instrument cluster: efficiency, visual capture, and satisfaction assessment for truck driving.

Research Paper

Abstract

This study aims at increasing knowledge on the best way to design trucks' gauges on digital instrument clusters. Trucks are equipped with many gauges that the driver has to monitor while driving. Digital instrument clusters offer new design possibilities and the human factors literature presents only limited answers on safe and efficient gauge designs. Eighteen truck drivers were presented with eight gauges with different shapes, orientation and indicators to perform three reading tasks (quantitative, qualitative and check reading). Results showed that gauge design impacted task completion times, eyes on-gauge duration and satisfaction. Horizontal gauges and pointer indicators were more efficient and less demanding visually. On the subjective side, circular and horizontal gauges were preferred by drivers. Specific gauge designs implied a gain in visual demand up to $250 \mathrm{~ms}$. For the design of gauges on digital instrument cluster, information processing can be facilitated thanks to basic design changes.

Taxonomy

Corresponding Author

Order of Authors

Suggested reviewers
Cognitive Ergonomics, Display-Control Relationship, Control Design, Design Control

Jordan Navarro

Mathilde François, Alexandra Fort, Philippe Crave, François Osiurak, Jordan Navarro

Catherine Harvey, Klaus Bengler, Julien Cegarra

\section{Submission Files Included in this PDF}

\section{File Name [File Type]}

Highlights.docx [Highlights]

Francois_MS.docx [Manuscript File]

To view all the submission files, including those not included in the PDF, click on the manuscript title on your EVISE Homepage, then click 'Download zip file'. 


\section{Highlights}

- Different gauge designs are best for different reading tasks

- Horizontal gauges and pointer indicator are more efficient and less visually demanding

- Circular and horizontal gauges are preferred by truck drivers

- For quantitative reading, eyes on-gauge time can be decreased by $280 \mathrm{~ms}$ by changing the design of a gauge 


\section{Gauges design for a digital instrument cluster:}

\section{2 efficiency, visual capture, and satisfaction}

\section{3 assessment for truck driving.}

Mathilde François ${ }^{1,2}$, Alexandra Fort ${ }^{3}$, Philippe Crave ${ }^{2}$, François Osiurak ${ }^{1,4}$, Jordan Navarro ${ }^{1,4}$ 5

${ }^{1}$ Laboratoire d'Etude des Mécanismes Cognitifs, Université de Lyon, Bron, France

$7 \quad 2$ Volvo Group Trucks Technology (GTT), Saint Priest, France

$8 \quad{ }^{3}$ Univ Lyon, IFSTTAR, TS2, LESCOT, F-69675, LYON, France

$9 \quad{ }^{4}$ Institut Universitaire de France, Paris, France

Corresponding author

Running head

15 Comparison of different gauge designs.

\section{Acknowledgement}

This work was performed within the framework of the LABEX CORTEX (ANR-11LABX-0042) of University of Lyon, within the program 'Investissements d'Avenir' (ANR-11IDEX-0007) operated by the French National Research Agency (ANR). The authors wish to thank Ghislaine Goullioud for the relevant advices during materials preparation. 


\title{
22 Gauges design for a digital instrument cluster: \\ 23 efficiency, visual capture, and satisfaction assessment for truck driving
}

\begin{abstract}
This study aims at increasing knowledge on the best way to design trucks' gauges on digital instrument clusters. Trucks are equipped with many gauges that the driver has to monitor while driving. Digital instrument clusters offer new design possibilities and the human factors literature presents only limited answers on safe and efficient gauge designs. Eighteen truck drivers were presented with eight gauges with different shapes, orientation and indicators to perform three reading tasks (quantitative, qualitative and check reading). Results showed that gauge design impacted task completion times, eyes on-gauge duration and satisfaction. Horizontal gauges and pointer indicators were more efficient and less demanding visually. On the subjective side, circular and horizontal gauges were preferred by drivers. Specific gauge designs implied a gain in visual demand up to $250 \mathrm{~ms}$. For the design of gauges on digital instrument cluster, information processing can be facilitated thanks to basic design changes.
\end{abstract}

40

Keywords

HMI design; Interface evaluation; Display design principles; Commercial vehicles dashboards; visual capture

Précis design possibilities. Eight different gauge designs were compared on three reading tasks: quantitative reading, qualitative reading and check reading. Human factors recommendations are provided in order to design gauges in a safe and efficient way. 
Within dashboards, gauges have always been major components. Oil level gauge was the first instrument installed inside vehicles around 1900 before speedometers (Akamatsu, Green \& Bengler, 2013). Nowadays, several gauges are displayed in automotive dashboards to monitor vehicle information, and this is especially true for trucks (Figure 1). Compared to cars, trucks' mechanical configuration and high amount of functions imply an increased amount of information to be monitored by the driver (e.g. up to two air pressure circuits, regeneration filters level, fuel additive tank level, etc.). Some truck gauges are monitored at vehicle start (e.g. air pressure gauge), but other gauges can be used while driving even in complex situations (e.g. fuel gauge). Attentional resources are required to monitor the different dynamic gauges. As a result, any improvements in gauge design would potentially translate into safely improvements of the driving task.

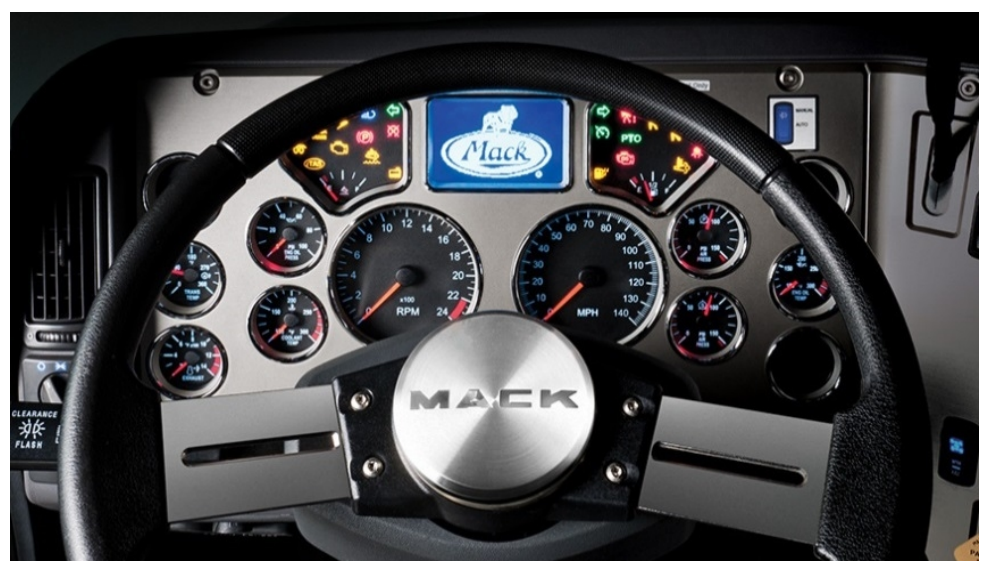

Figure 1. Example of 2016 truck dashboard (Mack Trucks North America, Series Granite)

Although literature on gauge design is extensive in related research areas, some knowledge is missing to define truck gauges, especially with the generalization of digital clusters that offers more design flexibility. More generally, we have identified five methodological limitations, preventing us to generalize the results obtained to the specific context of truck gauges. The first concerns the ecological nature of the task proposed. For instance, some of the results available in the literature have been obtained using the tachistoscopic method 
with controlled exposure time (e.g. 120ms in Sleight, 1948), which would affect results and be too far from what occurs in practice (Grether, 1949). The second concerns the lack of a systematic examination of each attribute on each reading type. Indeed, studies often compared few gauge attributes of very different designs, what does not allow judging the weight of each attribute and the interaction between them (Sleight, 1948). Thus, it is of particular interest to investigate how different gauge attributes impact on human monitoring. The third is the specificity of the task proposed in that most of the experiments carried out on the topic exclusively focus on the quantitative reading task (i.e. reading a number). In real life conditions, gauge monitoring implies not only quantitative reading (e.g. exact speed), but also other monitoring tasks, clearly identified in the Human Factors literature: quantitative reading, qualitative reading, and check reading (Endsley, 1988; Sanders and McCormick, 1993). 'Quantitative reading' is the processing of a precise numeric value (e.g. the engine speed value). 'Qualitative reading' is used to obtain a trend or change in direction (e.g. the quarter of the fuel level). 'Check reading' determines if a value is within a normal range or not (e.g. engine cooling temperature too hot). More data are thus required to assess the impact of gauge design on different reading tasks (i.e. qualitative reading and check reading). The fourth limitation is that some studies analyzed gauge performance with specified nature (e.g. air speed indicator; Grether \& Connell, 1948), what makes these results less transferable to other natures or new gauges. Considering "generic" gauges (without nature) would allow attributing results to design changes only, rather on the semantics associated. The fifth is the issue of transferability of results to the truck domain. More particularly, truck drivers' eye distance to the instrument cluster is greater and implies a larger visual angle compared to car driving. Moreover, truck drivers spend much time on the road in a professional context (up to $56 \mathrm{~h}$ in any given work week; Bedinger et al., 2015). Their expertise and their particular relation to the vehicle could impact their gauge monitoring process. To bypass these five methodological limitations, the present study proposes respectively: (1) to assess gauge reading during a driving activity; (2) to examine the effect 
of three gauge attributes in a systematic way; (3) to present drivers with three gauge reading tasks; (4) to present a generic gauge to increase the generalization of our results; and (5) to asses truck drivers. That being said, the next issue concerns the gauge attributes of interest. Today, gauge design is quite inconsistent across trucks manufacturers. Nevertheless, extensive research has been carried out for cars drivers (Green, 1984; Green, 1988; Mayer \& Laux, 1992) and aircraft pilots (Baker \& Grether, 1954; Connell, 1950; Grether, 1949; Grether \& Connell, 1948). Three main gauge types were investigated on the different reading tasks: counters or numeric displays, fixed pointer with moving scale, and moving pointer with fixed scale (Baker and Grether, 1954). Counters are reported fast and accurate for quantitative reading, but less suitable for qualitative and check reading (Baker \& Grether, 1954; Chapanis, 1960; Green, 1988; Grether, 1949; Sanders \& Mc Cormick, 1993). Fixed pointer with moving scale gauges would be globally poorly efficient on the three reading tasks compared to other gauge types (Baker \& Grether, 1954; Chapanis, 1960;

112 Connell, 1950; Green, 1988; Grether \& Connell, 1958). Moving pointer with fixed scale 113 display would be best for qualitative and check reading, and perform well on quantitative 114 reading (Baker \& Grether, 1954; Chapanis, 1960; Green, 1984; Green, 1988; Grether, 1949; 115 Grether \& Connell, 1958; Sanders \& Mc Cormick, 1993). This gauge type is also the main display used in current truck models. Nevertheless, many types of moving pointer with fixed scale exist, with different design attributes such as the marking of the scale, the way of numbering, the shape and orientation of the gauge, or the indicator type. These attributes have been subjects of several experiments and recommendations have been proposed. For instance, color coding would help the understanding and the detection of critical reading (Green, 1984; Mayer \& Laux, 1992); numbers for dials can be inside or outside the scale (Kappauf, 1951); scales should be marked in numbers that are even multiples of 10 (Green, 1988); aligning pointers to the normal value when multiple gauges have to be checked close to each other would reduce reading time and errors (Green, 1988; Warrick \& Grether, 1948); etc. In sum, previous experiments available in the literature have investigated a large set of 
gauges attributes (see Green, 1988 for a meta-analysis) but even more gauges' attributes could be envisioned. All those attributes cannot be manipulated experimentally in a single study. Thus, in this reported experiment the choice has been made to focus only on three major gauge attributes: shape, orientation and indicator.

In the past, those three gauges attributes have been reported to impact reading performance. In an early study in which participants were asked to perform quantitative reading (e.g. read an exact value on a scale), accuracy of reading the gauges were ranked as follows: open-window, circular, semi-circular, horizontal linear and vertical linear (Sleight, 1948). During brief presentation of gauges (10 sec films), the number of quantitative reading errors was found much higher for vertical linear gauges as compared to both horizontal linear and circular gauges (Graham, 1956). Circular gauges were also found more effective than vertical linear gauges when assessing the number of correct quantitative readings over five experimental sessions (Carveth \& Adams, 1964). Grether and Connell (1948, in Murrell, 1965, p.162) have suggested that vertical linear gauges are more effective than circular gauges because an upward movement of the pointer is always associated to an increase in value. The design of pointers has also been under the scope of investigation, but the design of a physical pointer itself only has a small effect on performances (see Green, 1988 for a review). Regarding the shape, orientation and indicator of gauges on preferences, previous research reported that circular gauges might be preferred to linear gauges (Carveth \& Adams, 1964; Graham, 1956; Green, 1988; Sleight, 1948), horizontal gauges to vertical gauges (Graham, 1956; Murrell, 1965; Sleight, 1948), and pointers to bargraphs (Mayer \& Laux, 1992).

148 As in-vehicle interfaces design may impact the driver's ability to perform the primary driving task while monitoring the cluster, it is essential to deliver to practitioners clear and directly applicable design requirements (François, Osiurak, Fort, Crave \& Navarro, 2016). This study addressed the following research questions: 
- What attributes really matter in gauge definition and do they interact?

- Which kinds of gauge displays are best for specific reading tasks?

155 Eight gauges were designed based on a factorial experimental design with three attributes: shape (circular or linear), orientation (horizontal or vertical), and indicator (pointer or bargraph). They were assessed on quantitative, qualitative, and check reading.

\section{Material and methods}

\subsection{Participants}

160 Eighteen trucks drivers took part in this experiment (all men, mean age: 43 years, SD: 5.3).

161 All participants held valid truck licenses for 13 years on average (SD: 8.6). Most participants 162 drove a truck several times a month (78\%). All reported normal or corrected-to-normal vision 163 and audition. Written informed consent was obtained from each participant.

\subsection{Equipment}

The fixed-base medium-fidelity driving simulator was composed of a truck seat, two thirds of a real dashboard, and a 65 inches plasma screen using Oktal SCANeR ${ }^{\mathrm{TM}}$ for traffic scenario and truck model. Throttle pedal, brake pedal, and steering wheel were original parts of a Renault Trucks T. A highway environment was used, with a random traffic around the vehicle. A 15.4 inches screen was located in place of the instrument cluster behind the steering wheel to display stimuli (height: $332 \mathrm{~mm}$, width: $207 \mathrm{~mm}$, resolution: 1280x800, refresh rate: $60 \mathrm{~Hz}$ ). A binocular head-mounted eye tracker was used to capture the eye gaze (Tobii Glasses 2; scene camera resolution: 1920×1080; eye camera tracking

174 frequency: $50 \mathrm{~Hz}$ ). Gaze raw data were filtered using the Tobii I-VT fixation filter configured 175 so that short fixations were not discarded (Olsen, 2012).

\subsection{Material}


Gauges. Eight gauges representations (Figure 2) were presented centered in upper half of

179 the screen. Gauges were generic (non-associated to a function, e.g. fuel level) for 180 generalizability reasons. They were presented without scale units. Scales were 181 monochromes, divided in 4 parts with internal graduations (block types), with the last half part in red to indicate a warning zone (always at the end of the gauge, such as for a temperature gauge type). A zero marker indicated the reading direction of the gauge. Three gauges attributes were presented and fully mixed resulting in eight gauge representations:

- Shape: Circular (demi circular gauge; diameter: $40 \mathrm{~mm}$ ) or Linear (length: $62.8 \mathrm{~mm}$ )

- Indicator: Pointer (length: $20 \mathrm{~mm} / 16 \mathrm{~mm}$ ) or Bargraph (white filling of the scale)
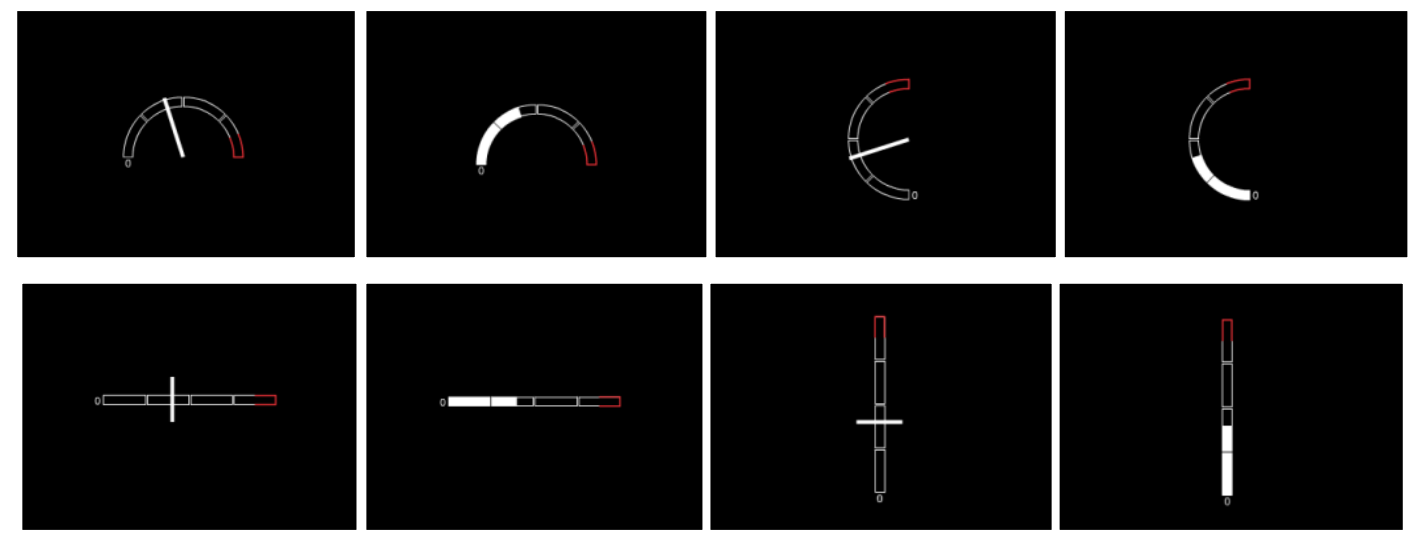

5.LPH

6.LBH

7.LPV

8.LBV

Figure 2. Gauge representations from Gauge 1 to Gauge 8. Each gauge is defined by its shape (C: Circular or L: Linear), its indicator (P: Pointer or B: Bargraph) and its orientation (H: Horizontal or V: Vertical).

Tasks performed. Participants were required to perform a primary driving task, which was to follow a red car on a highway. Moreover, each gauge was tested on three reading tasks: (answer: a number between 0 and 100) 
- Task 2 (qualitative reading): 'In which quarter is the gauge value?' (answer: one, two, three or four)

- Task 3 (check reading): 'Is the gauge value in the red zone or not?' (answer: yes or no)

For the tasks 1 and 2, four stimuli were presented for each gauge (1 with the value randomly chosen between 5 and 24; 1 between 25 and 49; 1 between 50 and 74; and 1 between 75 and 95). For the task 3, four stimuli were presented for each gauge (1 with the value randomly chosen between 8 and 47; 1 between 48 and 87; and 2 between 88 and 95).

\subsection{Procedure}

Before the experimental phase, participants were informed of the details of the study and completed a consent form. Afterwards, the eye tracking device was positioned and calibrated. For each test drive, participants were required to follow a red car on a highway. The question drivers had to answer was stated by the experimenter before departure. The information cluster remained black most of the time. Every 6 to $8 \mathrm{~s}$ (randomly) a sound announced that a gauge was about to be displayed. Thus the driver could give his answer aloud (that would remove the display). The experiment was composed of three test drives (a drive per reading task), all eight gauges designs were randomly presented in each drive four times. At the end of each test drive, participants were asked to rank the eight gauges by order of preference. This resulted in a gauge ranking per reading task. Each participant was tested individually and experienced all conditions. The order of the test drives was counterbalanced following Latin squares. The total test duration was approximately $1 \mathrm{~h}$.

\subsection{Data acquisition and analysis}

Efficiency was assessed through task completion times (i.e. time in millisecond between the display of a gauge and the answer of the participant) and accuracy scores (i.e. task 1: 
absolute distance between driver's answer and the real value displayed; task 2 and 3: error rate). Visual capture was analyzed through the total on-gauge glance duration from gauge display to the start of driver's aloud answer. Finally, driver satisfaction was assessed by gauge ranking in terms of preference (from 1 to 8,1 being the preferred gauge for each of the three reading tasks).

The results are reported dependent variable by dependent variable (i.e. efficiency, visual capture and satisfaction) with the same rationale. First, analyses were computed on gauge attributes (i.e. shape, indicator, and orientation) for the three tasks (i.e. quantitative, qualitative and check reading) to analyze global differences (regardless of the task). Second, for each task, a three-way repeated measures ANOVA was performed on the task completion times and total on-gauge glance duration (within-subject factors manipulated: shape with two modalities: circular and linear; indicator with two modalities: pointer and bargraph; and orientation with two modalities: horizontal and vertical). Tukey HSD tests were used as post-hoc analyses.

240 Regarding satisfaction ranking analyses, non-parametric Wilcoxon tests for paired samples and Friedman tests were performed. In addition, a hierarchical cluster analysis was also conducted on satisfaction scores (Ward's method applied to Euclidean distances).

\section{Results}

\subsection{Efficiency}

246 Global analysis. Task completion times (Figure 3) and accuracy scores were collected. A 247 significant main effect of the task was found $(F(2,34)=95.44, p<.001)$, post-hoc analyses showed that task $1(2058 \mathrm{~ms})$ implied longer task completion times that task $2(1232 \mathrm{~ms}$, $249 p<.001)$ and $3(1128 \mathrm{~ms}, p<.001)$.

250 The effect of orientation was also significant: tasks were performed slower with vertical 251 gauges $(1503 \mathrm{~ms})$ than with horizontal gauges $(1442 \mathrm{~ms} ; F(1,17)=12.20, p<.01)$. Similarly, 
tasks were performed slower with bargraph indicators (1498ms) than with pointers $(1447 \mathrm{~ms}$;

$253 F(1,17)=8.334, p<.01)$. The three-way interaction shape*orientation*indicator was 254 significant $(F(1,17)=13.84, p<.01)$ revealing that gauge 5 -LPH $(1401 \mathrm{~ms})$ was significantly more efficient than four other gauges (gauge 4-CBV: 1551ms, $p<.001$; gauge 6-LBH: 1495ms, $p<.001$; gauge 7-LPV: 1512ms, $p<.01$; gauge 8-LBV: 1490ms, $p<.03)$. On the contrary, Gauge 4-CBV was found less efficient than four other gauges (gauge 1-CPH: $1551 \mathrm{~ms}, p<.001$; gauge 2-CBH: 1495ms, $p<.001$; gauge $3-\mathrm{CPV}: 1512 \mathrm{~ms}, p<.01$; gauge $5-$ LPH). Gauge 7-LPV was significantly less efficient than gauge 5- LPH and gauge 1-CPH $260 \quad(1418 \mathrm{~ms}, p<.02)$.

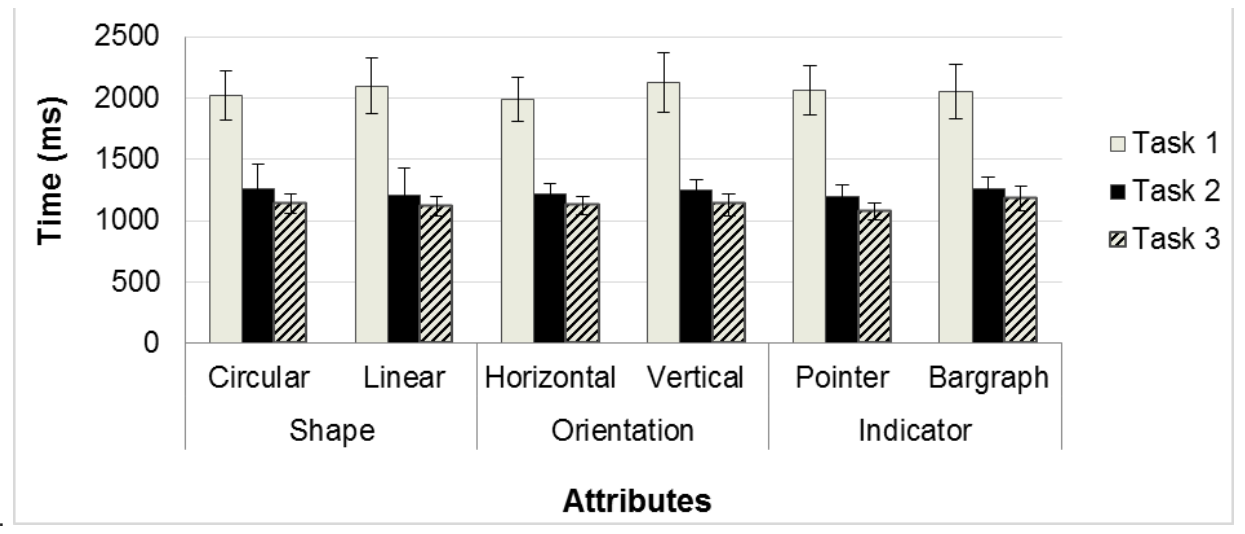

-Task 2 Task 3

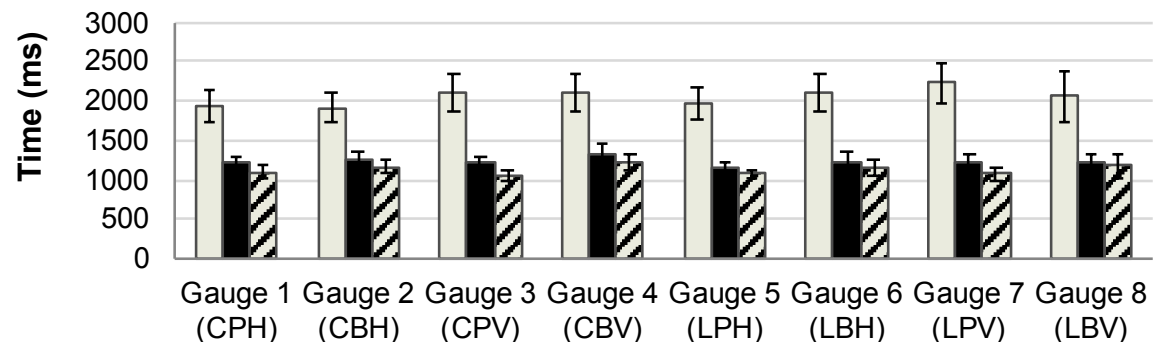

b.

Gauges

Figure 3. a. Task completion times in milliseconds ( \pm standard deviation) for the gauge attributes on the three tasks. 
Task by task analyses. For the task 1 (quantitative reading), tasks completion times were lower with horizontal $(1987 \mathrm{~ms})$ than with vertical gauges $(2128 \mathrm{~ms} ; F(1,17)=11.45, p<.01)$. The three-way interaction was significant $(F(1,17)=7.44, p<.02)$, and Tukey HSD post-hoc test showed that Task 1 was completed significantly faster with Gauge 1-CPH (1940ms, $p<.001)$, Gauge 2-CBH (1922ms, $p<.001)$ and Gauge 5-LPH $(1980 \mathrm{~ms}, p=<01)$ than with Gauge 7-LPV (2232ms). Reading accuracy was very good with about $2.5 \%$ of errors around the real value on the average and not significantly different between gauge attributes.

For the task 2 (qualitative reading), tasks completion times were lower with linear (1208ms) than with circular gauges $(1255 \mathrm{~ms} ; F(1,17)=8.19, p<.02)$. Horizontal gauges $(1215 \mathrm{~ms})$ were slightly more efficient than vertical gauges $(1248 \mathrm{~ms} ; F(1,17)=11.62, p<.01)$. Similarly, pointers $(1201 \mathrm{~ms})$ were slightly more efficient than bargraph indicators $(1262 \mathrm{~ms} ; F(1,17)=$ $8.39, p<.01)$. Accuracy was very good, with less than $2 \%$ of incorrect quarter responses, and not significantly different between gauge attributes. The three-way interaction was significant $(F(1,17)=5.55, p<.04)$, and Tukey HSD post-hoc test reported that task 2 was completed faster with the Gauge 1-CPH (1214ms, $p<.05)$, Gauge 3-CPV $(1215 \mathrm{~ms}, p<.05)$ and Gauge 5-LPH $(1147 \mathrm{~ms}, p<.05)$ than with Gauge 4-CBV $(1327 \mathrm{~ms})$. Gauge 5-LPH was more efficient than Gauge 2-CBH $(1266 \mathrm{~ms}, p<.04)$ and Gauge 4-CBV. The Friedman test reported no significant difference of accuracy between gauge attributes.

For the task 3 (check reading), tasks were completed faster with pointer gauges $(1076 \mathrm{~ms})$ than with bargraph gauges $(1180 \mathrm{~ms} ; F(1,17)=21.13, p<.001)$. Accuracy was extremely good, with less than $1 \%$ of incorrect responses, and not significantly different between gauge attributes.

\subsection{Visual capture}

292 Global analyses. Visual capture was assessed through the total on-gauge glance duration

293 (Figure 4). A main effect of the task was found significant $(F(2,34)=115.12, p<.001)$, 
showing that task $1(1214 \mathrm{~ms})$ implied longer on-gauge glances than task $2(673 \mathrm{~ms}, p<.001)$ and task $3(600 \mathrm{~ms}, p<.001)$. Regardless of the task, vertical gauges $(860 \mathrm{~ms})$ appeared more visually demanding than horizontal gauges $(798 m s ; F(1,17)=25.46, p<.001)$. On-gauge glance durations were also longer with bargraph gauges $(863 \mathrm{~ms})$ than with pointer indicator gauges $(795 \mathrm{~ms} ; \quad F(1,17)=20.13, \quad p<.001)$. The three-way interaction shape*orientation*indicator was also significant $(F(1,17)=9.66, p<.01)$, and post-hoc test reported that Gauge 5-LPH $(731 \mathrm{~ms})$ was significantly less visually demanding than four other gauges (Gauge 2-CBH: 840ms, $p<.03$; Gauge 4-CBV: 915ms, $p<.001$; Gauge 7-LPV: 870ms, $p<.01$; and Gauge 8-LBV: 864ms, $p<.01$ ). On the contrary, Gauge 4-CBV implied longer on-gauge glances than four other gauges (Gauge 1-CPH: $p<.01$; Gauge 3-CPV: $p<.01$; and Gauge 5-LPH).

305

306

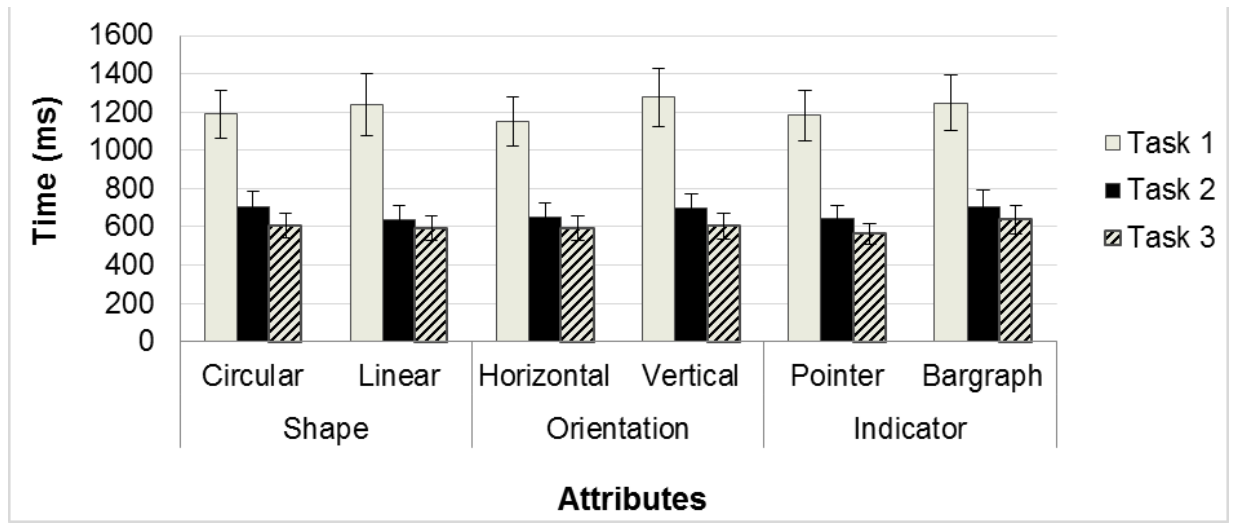
口Task 1 -Task 2 aTask 3

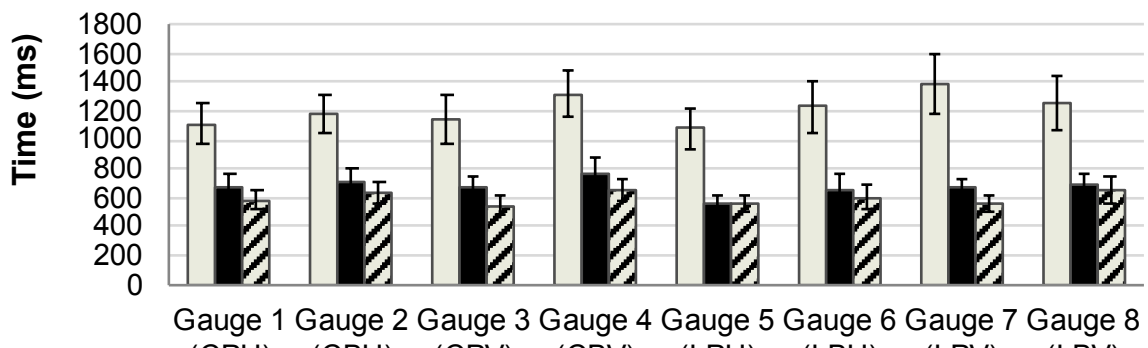

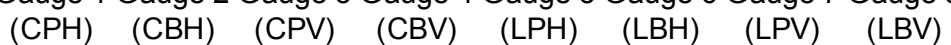

b.

Gauges 
Figure 4. a. Total on-gauge glance duration in milliseconds ( \pm standard deviation) for the gauge attributes on the three tasks.

b. Total on-gauge glance duration in milliseconds ( \pm standard deviation) for the eight gauges on the three tasks.

Task by task analyses. For the task 1 (quantitative reading), the main effect of orientation was significant $(F(1,17)=11.71, p<.01)$ showing that vertical gauges $(1277 \mathrm{~ms})$ were more visually demanding than horizontal gauges $(1151 \mathrm{~ms})$. The three-way interaction shape*orientation*indicator was also significant $(F(1,17)=6.96, p<.02)$ showing that Gauge

7-LPV (1382ms) was more visually demanding than Gauge 1-CPH (1112ms, $p<.03)$ and Gauge 5-LPH (1084ms, $p<.02)$.

For the task 2 (qualitative reading), main effects of shape, orientation, and indicator factors reached significance. Circular gauges $(706 \mathrm{~ms})$ were more visually demanding than linear gauges $(640 \mathrm{~ms} ; F(1,17)=19.37, p<.001)$. Vertical gauges $(698 \mathrm{~ms})$ were more visually demanding than horizontal gauges $(648 \mathrm{~ms} ; F(1,17)=27.34, p<.001)$. Bargraph gauges (704ms) were more visually demanding than pointer gauges $(642 \mathrm{~ms} ; F(1,17)=15.67$, $p<.001)$. The three-way interaction was significant $(F(1,17)=8.24, p<.02)$, and Tukey HSD post-hoc test reported that task 2 implied longer eyes on-gauge duration with Gauge 4-CBV (769ms) than with five other gauges (Gauge 1-CPH: 675ms, $p<.05$; Gauge 3-CPV: 673ms, $p<.04$; Gauge 5-LPH: 553ms, $p<.001$; Gauge 6-LBH: 658ms, $p<.02$; and Gauge 7-LPV: $665 \mathrm{~ms}, p<.03)$. On the contrary, Gauge $5-\mathrm{LPH}$ was less visually demanding than all other gauges (Gauge 1-CPH: $p<.01$; Gauge 2-CBH: 706ms, $p<.001$; Gauge 3-CPV: $p<.01$; Gauge 4-CBV; Gauge 6-LBH: $p<.02$; Gauge 7-LPV: $p<.02$; and Gauge 8-LBV: 683ms, $p<.01$ ).

For the task 3 (check reading), the effect of the indicator was significant: pointer gauges (562ms) were less visually demanding than bargraph gauges $(637 \mathrm{~ms} ; F(1,17)=25.59$, $p<.001)$. The two-way interaction orientation*indicator was also significant $(F(1,17)=4.75$, $p<.05$ ), showing that the effect of the indicator is more pronounced for vertical (vertical- 
pointer gauges: $554 \mathrm{~ms}$, vertical-bargraph gauges: $654 \mathrm{~ms} ; p<.001)$ than for horizontal gauges (horizontal-pointer gauges: $571 \mathrm{~ms}$, horizontal-bargraph gauges: $621 \mathrm{~ms} ; p<.04$ ).

\subsection{Satisfaction}

Global analyses. Pairwise comparisons were led for each attribute using Wilcoxon tests 340 (Figure 5a). Globally, circular gauges (mean score: 11.17) are preferred to linear gauges 341 (4.10; $Z=3.223, p<.001)$. Similarly, horizontal gauges $(9.04)$ are preferred to vertical gauges 342 (6.22; $Z=3.462, p<.001)$.

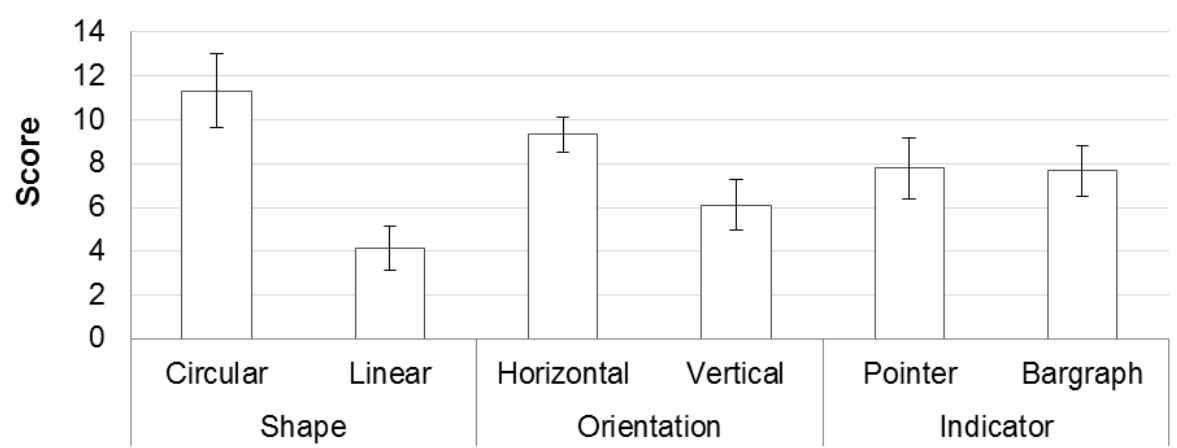

a. Attributes

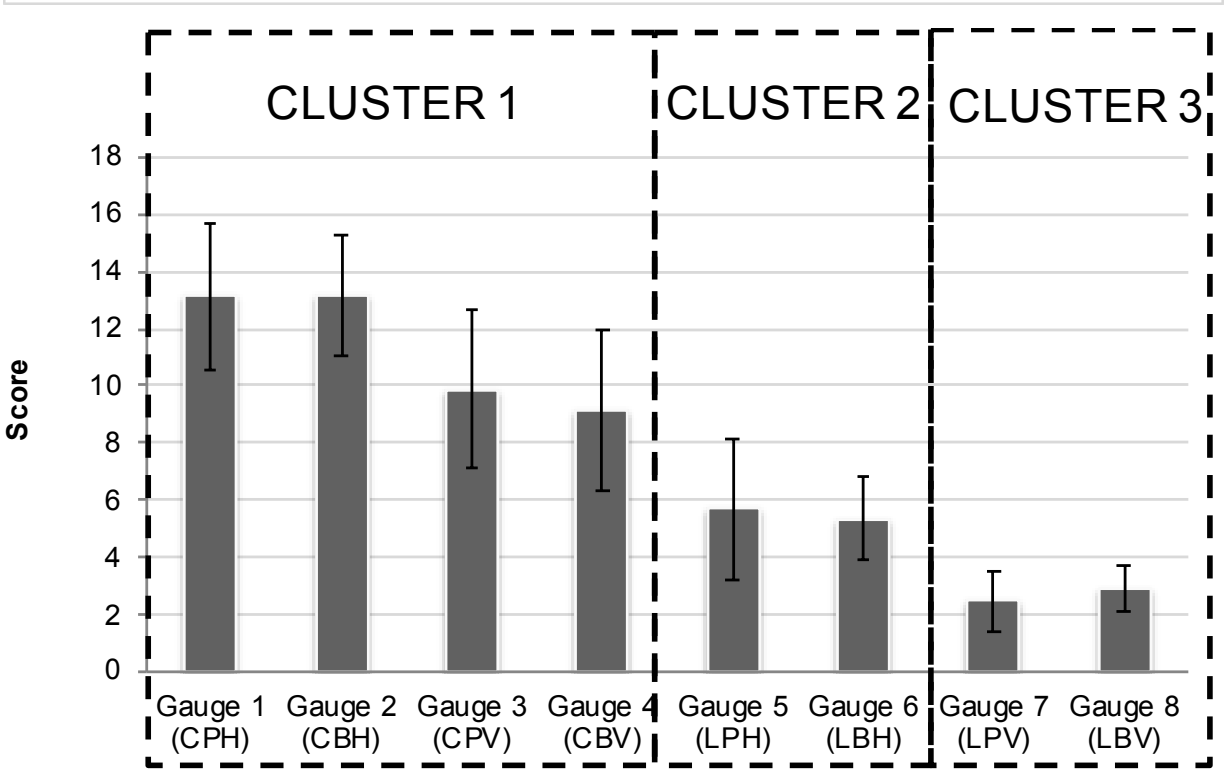


Task by task analyses. Friedman test reported significant differences between gauges

$351\left(X^{2}(7)=70.70, p<.001\right)$. Because very similar satisfaction results were found for the three 352 reading tasks, the analyses are presented together. The effect of the shape was significant 353 (circular or linear; task 1: respectively 11.17 and $4.10, Z=3.223, p<.001$; task 2: 11.39 and 354 4.22, $Z=3.092, p<.01$; task $3: 11.43$ and $4.06, Z=3.593, p<.001)$, such as the effect of orientation (horizontal or vertical; task 1: respectively 9.04 and $6.22, Z=2.548, p<.02$; task 2 : 9.38 and $6.24, Z=2.417, p<.02$; task $3: 9.60$ and $5.89, Z=3.332, p<.001)$.

A hierarchical cluster analysis enables to gather the eight gauges into clusters which would correspond to different satisfaction levels (Figure $5 b$ ). Three clusters resulted from the analysis: a first cluster with the highest satisfaction level (Gauge 1-CPH: mean score: 13.11; Gauge 2-CBV: 13.17; Gauge 3-CPV: 9.87; and Gauge 4-CBV: 9.17); a second cluster with a mid-satisfaction level (Gauge 5-LPH: 5.70; and Gauge 6-LBH: 5.37); a third cluster with the lower satisfaction level (Gauge 7-LPV: 2.48; and Gauge 8-LBV: 2.94).

\section{Discussion}

365 Based on these results, answers to the research questions are listed below.

\subsection{Does gauge design impact efficiency, visual capture and satisfaction?}

367 First, not significant differences were observed between the different gauges attributes in terms of reading accuracy. All gauges offered drivers the possibility to complete the three different reading tasks very accurately. In the most difficult reading task, where drivers were expected to give an exact value (i.e. Task 1: quantitative reading), the average accuracy error was of about $2.5 \%$. The accuracy was even better for quantitative and check reading, with inaccuracy frequency respectively under $2 \%$ and $1 \%$. This could be explained by the experimental design were drivers could look at the gauge as long as needed to complete the

374 reading task. Thus, the most sensitive variable to assess efficiency was the task completion time. These results were supplemented by on-gauge glace duration in order to dissociate the 
376 time required by drivers to perceive the required information on the gauge displayed (i.e. on-

377 gauge glance duration) from the time required to perceive, process and respond to that 378 information. The results collected in terms of task completion time and on-gauge glance 379 duration were very consistent and were found to be dependent of the reading task considered. Depending on the reading task, each of the three gauges attributes manipulated (i.e. shape, indicator and orientation) was found to impact visual capture and completion times. Those differences are discussed in the following paragraphs.

Second, generally speaking, no dramatic effect size changes from one gauge design to the other were observed. At most, a difference of on-gauge glance duration of $280 \mathrm{~ms}$ was observed between two gauge designs. Although such duration is short in absolute terms, in the truck-driving context this time difference might have a dramatic impact on safety. For instance while driving at $110 \mathrm{kph}$ on a highway, the vehicle is moving by about 8.5 meters during $280 \mathrm{~ms}$. Depending on the context, such a distance might be sufficient to prevent or cause a crash for instance.

Third, objective results were found inconsistence with subjective results collected on drivers satisfaction. Drivers reported a clear preference for circular gauges even if little difference in terms of performance was found between circular and linear gauges. Similarly, Gauge 4 (circular-vertical-bargraph) was part of the higher satisfaction cluster, even if its performance measures were lower than other gauges. On the contrary, Gauge 5 (linear-horizontalpointer) implied good objective results and was part of the mid-satisfaction cluster. Such a pattern of results has already been observed for driving assistance for instance with less effective assistance devices being preferred by drivers over more effective devices (Navarro et al., 2010). Driver preference could rely on other factors than performance, such as aesthetics or familiarity (Alexandre et al, 2018; Kurosu \& Kashimura, 1995). This 400 inconsistency between objective and subjective results cause a dilemma to in-vehicle dashboard designers. What should be favored customers' safety or customers' satisfaction? At a first glance one might think that picking safety is best even is that would come with a 
lower level of satisfaction. But what if customers' simply buy or use another vehicle with a

404 more satisfying interface? A design offering a good compromise between efficiency and satisfaction could be considered as a valuable alternative.

\subsection{What attributes really matter in gauge definition?}

408

409

410

411

412

413

The shape of the gauge had a high impact on satisfaction. Circular gauges were clearly preferred by drivers compared to linear gauges. However, the shape was not determining on objective measures. An effect of the shape was only found for the qualitative reading (Task 2 ), with a low impact on task completion (gap of $47 \mathrm{~ms}-4 \%$ ) and eyes on-gauge times (gap of $66 \mathrm{~ms}-9 \%)$. The superiority of circular gauges on linear gauges in terms of preference was also observed in previous researches (Carveth \& Adams, 1964; Graham, 1956; Green, 1988; Sleight, 1948). Mayer and Laux (1992) reported however no effect on detection reaction times, but an impact on the primary task. In the reported experiment, driving performances analysis was not technically possible. In the future, it would be interesting to investigate how the gauges design impacts driving performance.

The orientation of the gauge had a more significant impact on objective criteria. Horizontal gauges were more efficient and less visually demanding than vertical gauges (gap of 126ms - 10\%). Moreover, horizontal gauges were greatly preferred by drivers. These results, consistent with previous findings (Graham, 1956; Murrell, 1965; Sleight, 1948), have been explained by physiological reasons. Indeed, the visual field being wider than taller, horizontal eye movements would be easier than vertical ones (Green, 1988).

The indicator type had a low implication in gauge efficiency (gap of 50ms - 3\%) and visual demand (gap of $65 \mathrm{~ms}-8 \%$ ). Connell (1950) proposed that the surface of the indicator would help detection, which could explain the benefit of a pointer against a bargraph. Indicator was also not decisive in drivers' order of preference. 
430 For gauges requiring quantitative reading (Task 1; e.g. tachometer), horizontal gauges were 431 more efficient and less demanding visually. Eyes on-gauge duration was decreased by $432126 \mathrm{~ms}(10 \%)$ compared to vertical gauges. The indicator type also impacted visual capture, 433 but less significantly, with an eyes on-gauge duration decreased by $65 \mathrm{~ms}$ (5\%). Linear434 vertical-pointer gauges (Gauge 7) should be avoided, considering that they implied a visual 435 capture increased by about $280 \mathrm{~ms}(20 \%)$ compared to other gauge design (Gauge 1: 436 circular-horizontal-pointer or Gauge 5: linear-horizontal-pointer should be preferred). This 437 difference is particularly significant, considering that $280 \mathrm{~ms}$ represents a driven distance of 7 438 meters at $90 \mathrm{~km} / \mathrm{h}$.

439 For gauges requiring qualitative reading (Task 2; e.g. fuel gauge), effects of attributes were 440 less substantial. Linear gauges were more efficient and less visually demanding than circular 441 gauges, with a reduction of eyes on-gauge duration by $66 \mathrm{~ms}(9 \%)$. Pointer indicators implied 442 a visual captre decrease of $62 \mathrm{~ms}(9 \%)$, and horizontal gauges of $49 \mathrm{~ms}(7 \%)$. Moreover, the 443 gauge combining these attributes clearly marked out (Gauge 5: linear-horizontal-pointer 444 gauge). Significant gains (between $100 \mathrm{~ms}$ and $210 \mathrm{~ms}-16 \%$ and $29 \%$ ) were measured in 445 term of visual capture. On the contrary, circular-vertical-bargraph gauges (Gauge 4) should 446 be avoided for this task, considering that Gauge 4 was less efficient and more visually 447 demanding than four other gauge designs (eyes on-gauge duration increased by $124 \mathrm{~ms}$ in 448 average $-16 \%)$.

449 For gauges requiring check reading (Task 3; e.g. engine cooling temperature gauge), pointer 450 indicators were more efficient and less visually demanding than bargraph indicators (visual 451 capture decreased by $75 \mathrm{~ms}-12 \%)$. The differences between gauges did not match 452 significance, showing that gauge design would be less impacting for this task.

\subsection{Limitations and perspectives}


455 This study contributes to the current knowledge on this topic, by adding satisfaction data, 456 and by deepening evidence on the role and weight of different design attributes on 457 information processing. However, future research should address further issues. First, no 458 meaning (e.g. oil pressure) was assigned to the values displayed. Thus, the resulting 459 requirements can be applied to new natures of gauges. Nevertheless, gauges can be 460 symbolic or pictorial (i.e. graphical resemblance with the conditions represented). Another 461 widely acknowledged human factor principle is to support driver's mental model of reality 462 (Ross et al., 1996). For example, the gauge displaying fuel level can be considered as an 463 analogy of the fuel tank. Based on this principle, fuel gauges would be best vertically, even if 464 vertical gauges were found less efficient in this study. Appropriate trade-offs between 465 competing requirements should be assessed according to the nature of the gauge.

466 Second, gauges were assessed individually on each of the three reading tasks. In a vehicle, 467 the same gauge can be used for different reading. For instance, the gauge of air pressure 468 could be used to judge the rate of increase at starting up (i.e. qualitative reading), to set the 469 pressure at a specific value (i.e. quantitative reading), or to ensure that the system is not 470 impaired (i.e. check reading). The requirements for these different uses may conflict, and it 471 will be necessary to evaluate which is the main reading task (based on relevancy for driving, 472 criticality, urgency, and frequency of use criteria).

473 Third, gauges were here presented in isolation for finer experimental control. Reading can 474 yet be affected by the layout and the clutter of the cluster. High information clutter may 475 cause overload, increased errors, and difficulties in finding appropriate information (Stevens, 476 Quimby, Board, Kersloot, \& Burns, 2002). Gauges may also be operated interdependently 477 (e.g. speedometer and tachometer readings) and the arrangement of multiple gauges has 478 been showed relevant (Green, 1988; Warrick \& Grether, 1948). A perspective would be to 479 evaluate if each gauge of a truck dashboard should be designed according to its main 480 reading type (based on the results of this study), or if consistency should be applied. Mayer 
481 and Laux (1992) provided a start of an answer reporting that combining dissimilar designs

482 would not make it harder to detect critical values on one gauge.

483

484

4855 Conclusions

486 Gauges are major components of trucks dashboards, with direct safety considerations. It is 487 therefore essential to deliver design requirements to practitioners with the following 488 objectives: to provide the information in a quick and accurate way to the driver, and to 489 minimize eyes- on-gauge duration. With the arrival of digital instrument clusters, the human 490 factors literature presents only limited answers to contemporary concerns. This experiment 491 updated existing literature and deepened knowledge on the design attributes impact on 492 gauge information processing. Our findings have direct design implications for surface 493 vehicles dashboards: globally, horizontal gauges and pointer indicators should be favoured 494 in terms of performance and circular gauges are preferred by drivers; gauges requiring 495 quantitative reading should be horizontal and linear-vertical-pointer gauges should be 496 avoided; gauges requiring qualitative reading should be linear and circular-vertical-bargraph 497 gauges should be avoided; gauges requiring check reading should have pointer indicators. 498 The linear-horizontal-pointer gauge performed well on all reading tasks (see Gauge 5, Figure 499 2). 


\section{References}

502

Alexandre, B., Reynaud, E., Osiurak, F., \& Navarro, J. (2018). Acceptance and acceptability criteria: a literature review. Cognition, Technology \& Work, 1-13.

Akamatsu, M., Green, P., \& Bengler, K. (2013). Automotive technology and human factors research: Past, present, and future. International Journal of Vehicular Technology, 2013.

Baker, C. A., \& Grether, W. F. (1954). Visual presentation of information. (WADC Technical Report 43064). Wright-Patterson AFB, OH: Wright Air Development Center. trajectory for ergonomics and road freight. Applied Ergonomics, 53, 343-356.

510 Carveth, J. W., \& Adams, J. A. (1964). Effects of practice on dial reading. Human Factors:

511 The Journal of the Human Factors and Ergonomics Society, 6, 81-85. University, Psychology Department. Technical Report 6024). Wright-Patterson AFB, OH: Wright Air Development Center.

517 Dillon, A. (1992). Reading from paper versus screens: A critical review of the empirical 518 literature. Ergonomics, 35, 1297-1326.

519 Endsley, M. R. (1988). Situation awareness global assessment technique (SAGAT).

520 Paper presented at the National Aerospace and Electronic Conference (NAECON), Dayton, $521 \mathrm{OH}$.

522 François, M., Crave, P., Osiurak, F. Fort, A., \& Navarro, J. (2017). Digital, analogue, or 523 redundant speedometer for truck driving: impact on visual distraction, efficiency and 524 usability. Applied ergonomics, 65, 12-22. 

design and participatory user involvement: Review and perspectives. Ergonomics, 60(4), $541-552$.

528 Graham, N.E. (1956). The Speed and Accuracy of Reading Horizontal, Vertical, and

529 Circular Scales, Journal of Applied Psycholog, 40, 228-232.

530 Green, P. (1984). Driver understanding of fuel and engine gauges (No. 840314). SAE 531 Technical Paper.

532 Green, P. (1988). Human factors and gauge design: a literature review (No. UMTRI-88533 37). The University of Michigan Transportation Research Institute.

534 Grether, W.F. (1949). Instrument reading I: the design of long scale indicators for speed 535 and accuracy of quantitative readings. Journal of Applied Psychology, 33, 363-372.

536 Grether, W.F., \& Connell,S.C. (1948). Psychological factors in check reading of single 537 instruments (WADC Technical Report 4803). Wright-Patterson AFB, OH: Wright Air 538 Development Center.

539 Kappauf, W.E. (1951). Design of Instrument Dials for Maximum Legibility: Part 5. Origin 540 Location, Scale Break, Number Location, and Contrast Direction, (WADC Technical Report 541 6366). Wright-Patterson AFB, OH: Wright Air Development Center.

542 Kurosu, M. \& Kashimura, K. (1995). Apparent Usability vs. Inherent Usability:

543 Experimental analysis on the determinants of the apparent usability. Proceedings ACM 544 CHI95 Conference (pp. 292-293), New York: ACM Press

545 Mangen, A., Walgermo, B. R., \& Brønnick, K. (2013). Reading linear texts on paper 546 versus computer screen: Effects on reading comprehension. International Journal of 547 Educational Research, 58, 61-68.

548 Mayer, D. L., \& Laux, L. F. (1992). Evaluating Vehicle Displays for Older Drivers. AAA 549 Foundation for Traffic Safety. 
550 Murrell, H. (1965). Design Factors III. Design of Instrumental Displays. In Ergonomics:

551 Man in His Working Environment (pp. 154-215). Netherlands: Springer.

552 Navarro, J., Mars, F., Forzy, J. F., El-Jaafari, M., \& Hoc, J. M. (2010). Objective and 553 subjective evaluation of motor priming and warning systems applied to lateral control 554 assistance. Accident Analysis \& Prevention, 42(3), 904-912.

555 Olsen, A. (2012). The tobii i-vt fixation filter. Tobii Technology.

556 Ross, T., Midtland, K., Fuchs, M., Pauzie, A., Engert, A., Duncan, B., Vaughan, G., 557 Vernet, M., Peters, H., Burnett, G., \& May, A. (1996). HARDIE Design Guidelines Handbook: 558 Human Factors Guidelines for Information Presentation by ATT Systems.

559 Sanders, M. S., \& McCormick, E. J. (1993). Human factors in engineering and design. 560 New York: McGraw-Hill.

561 Sleight, R. B. (1948). The effect of instrument dial shape on legibility. Journal of Applied 562 Psychology, 32, 170.

563 Stevens, A., Quimby, A., Board, A., Kersloot, T., \& Burns, P. (2002). TRL - Design 564 guidelines for safety of in-vehicle information systems.

565 Warrick, M.J.,\& Grether, W.F. (1948). The Effect of Pointer Alignment on Check Reading 566 of Engine Instrument Panels (WADC Technical Report 69417). Wright-Patterson AFB, OH:

567 Wright Air Development Center. 


\section{Biographies}

569

570 Mathilde François is an industrial PhD student in Cognitive Science at Volvo Group Trucks

571 Technology and University Lyon 2 (E.M.C laboratory). She graduated from University Lyon 2

572 with a Master's degree in Cognitive Science in 2013.

573 Alexandra Fort is a researcher at the Laboratory Ergonomics and Cognitive Sciences 574 applied to Transport (IFSTTAR-TS2). She obtained a PhD in Cognitive Science at University 575 Lyon 2 in 2002.

576 Philippe Crave is an HMl designer for more than 10 years at Volvo Group Trucks

577 Technology. He received his Master's degree in Mechanical engineering from University of

578 Technology of Compiègne (UTC) in 1999.

579 François Osiurak is a Full Professor in Neuropsychology at the University Lyon 2 (E.M.C.

580 laboratory) and appointed as Junior Member at of the "Institut Universitaire de France". He

581 received a PhD in Psychology from the University of Angers in 2007.

582 Jordan Navarro is lecturer in cognitive psychology at the University Lyon 2 (E.M.C 583 laboratory) and appointed as Junior Member at of the "Institut Universitaire de France". He 584 graduated from the University of Nantes with a PhD in Psychology in 2008. 